\title{
Re-Formative Polymer Composites from Plastic Waste: Novel Infrastructural Product Application
}

\author{
Richard P. Turner ${ }^{1, *}$, Catherine A. Kelly ${ }^{1}{ }^{1}$, Rod Fox $^{2}$ and Bill Hopkins ${ }^{2}$ \\ 1 School of Metallurgy and Materials, University of Birmingham, B15 2TT Birmingham, UK; \\ c.a.kelly@bham.ac.uk \\ 2 Revaluetech Ltd, PO Box 16170, B13 3LN Birmingham, UK; rodfox@revaluetech.co.uk (R.F.); \\ billhopkins@revaluetech.co.uk (B.H.) \\ * Correspondence: R.P.Turner@bham.ac.uk
}

Received: 13 September 2018; Accepted: 21 November 2018; Published: 23 November 2018

\begin{abstract}
A novel re-formative polymer composite manufacturing route has been developed by UK and Qatar-based Universities. This novel process recycles domestic-waste thermoplastic material, without the requirement for intensive filtering or washing operations. The produced polymer can be reinforced with recycled glass fibres, forming a structurally load-bearing composite, which may potentially be suitable for use in applications, including utility poles, railway sleepers, and fencing. Thus, infra-red (IR) analysis showed the presence of polypropylene (PP), polyethylene $(\mathrm{PE})$, and polyethylene terephthalate (PET) in the commingled material. Differential scanning calorimetry (DSC) was used to determine glass transition temperatures and melting temperatures of each of the associated polymer types. Dynamic mechanical thermal analysis (DMTA) was used to determine the storage and loss modulus of the bulk commingled component. Lastly, flexural and tensile strengths of the re-formative polymer with differing proportions of glass fibre were assessed, giving a range of strengths at each glass fibre proportion for possible compositional variation in the polymer type. The recycled polymer is considered a viable structural material for replacing both wooden and concrete components, generating a polymer recycling route with concomitant environmental benefits. This plastic recycling route therefore offers a solution towards achieving climate change targets with a purposeful end-product component.
\end{abstract}

Keywords: plastic recycling; pollution reduction; structural components; thermoplastic; glass fibre

\section{Introduction}

\subsection{Plastic Production and Pollution}

Man-made polymer materials can be generally sub-sectioned into thermoset and thermoplastic polymers. Thermoplastic polymers become soft and pliable when they exceed the glass transition temperature, and then solidify again upon cooling [1]. Examples of thermoplastic polymers include low and high density polyethylene (LDPE, HDPE), polyethylene terephthalate (PET), polypropylene (PP), and polystyrene (PS). Whereas thermoset polymers become irreversibly hardened through a chemical curing process, such that even re-heating cannot re-melt a thermoset. This permanent change occurs due to cross-linking of the polymer chains [1], and makes thermoset plastics largely unsuitable for recycling. However, domestic and industrial packaging material is formed from thermoplastic polymers, which make up approximately $80 \%$ of manufactured plastics [2].

As of 2011, the worldwide annual production of plastic reached 300 million tonnes, yet worldwide plastic recycling contributed to only $10 \%$ of this production [3]. The UK has a higher reported plastics recycling rate than the worldwide average, at an estimated 33\% [4,5]. However recent reports [6] 
suggest that the UK recycling rate figure may be artificially inflated by a considerable amount of plastic each year sent abroad for recycling, which may simply end up in foreign landfill sites. Yet, although it is far from desirable for plastics to end up in landfill, there is an even worse destination for them. Plastic pollution describes the discarding of plastic items, which enter the environment in an uncontrolled, unmonitored fashion. Plastic pollution often reaches the oceans, which causes problems for marine life, and in turn the potential of ingestion of plastic by humans through the food chain.

The increasing production of plastics on a global scale is startling. In the previous decade, more plastic has been produced than during the entire 20th century [7]. This exponential growth in plastics production is due to the so called 'plastics revolution' whereby chemists are developing new methods to push the limits of polymers [8]. However, new environmental regulations are beginning to target plastic products, such as micro-plastics [9].

Several detailed literature reviews have been composed to highlight the current perceived state-of-the-art plastic recycling methods over the past 20 years, from Brandrup [10], to Mantia [11], to Karlsson [12]. These reviews illustrate novel approaches toward plastic recycling, including blending of the recycled material with virgin polymer, the use of additives to stabilise formulations, studies on the compatibilization of different mixed plastic types, and reinforcement of polymers with natural fibres or glass fibres to produce composite material with superior mechanical properties $[13,14]$.

Currently, there is a groundswell of support for a considerable societal change to plastic usage throughout the developed world $[15,16]$, with the primary concern upon: (i) Single-use plastics, such as food and domestic packaging; and (ii) improvement of plastic recycling schemes.

Conventional domestic waste plastic recycling methods include only a few types of plastic packaging, namely low density polyethylene (LDPE), high density polyethylene (HDPE), and polypropylene (PP) [17], and often the recycled material needs to be processed in ways that reduce contamination [18].

Thus, current recycling methods involve filtering for size and type, a comprehensive washing and separation operation, crushing, drying, and granulation (see Figure 1) to produce a recycled resin pellet product that can be utilised [17]. However, low economic value of waste plastic, and the difficult filtering process, causes low plastic recycling rates [19]. Additionally, the recycled plastic can suffer degradation in properties compared to virgin polymers, often due to heating when processing, contamination, and immiscibility of differing polymer grades [18]. Phase-separation of different plastics produces phase boundaries within the formed product, which limits their potential use. The only method to eliminate phase separation is to manually sort and separate plastics prior to crushing and shredding, according to their resin identification. Current applications for the relatively small percentage of plastic components that are manufactured using recycled plastics include non-food packaging, traffic bollards and signage, garden furniture, and plastic lumber. 


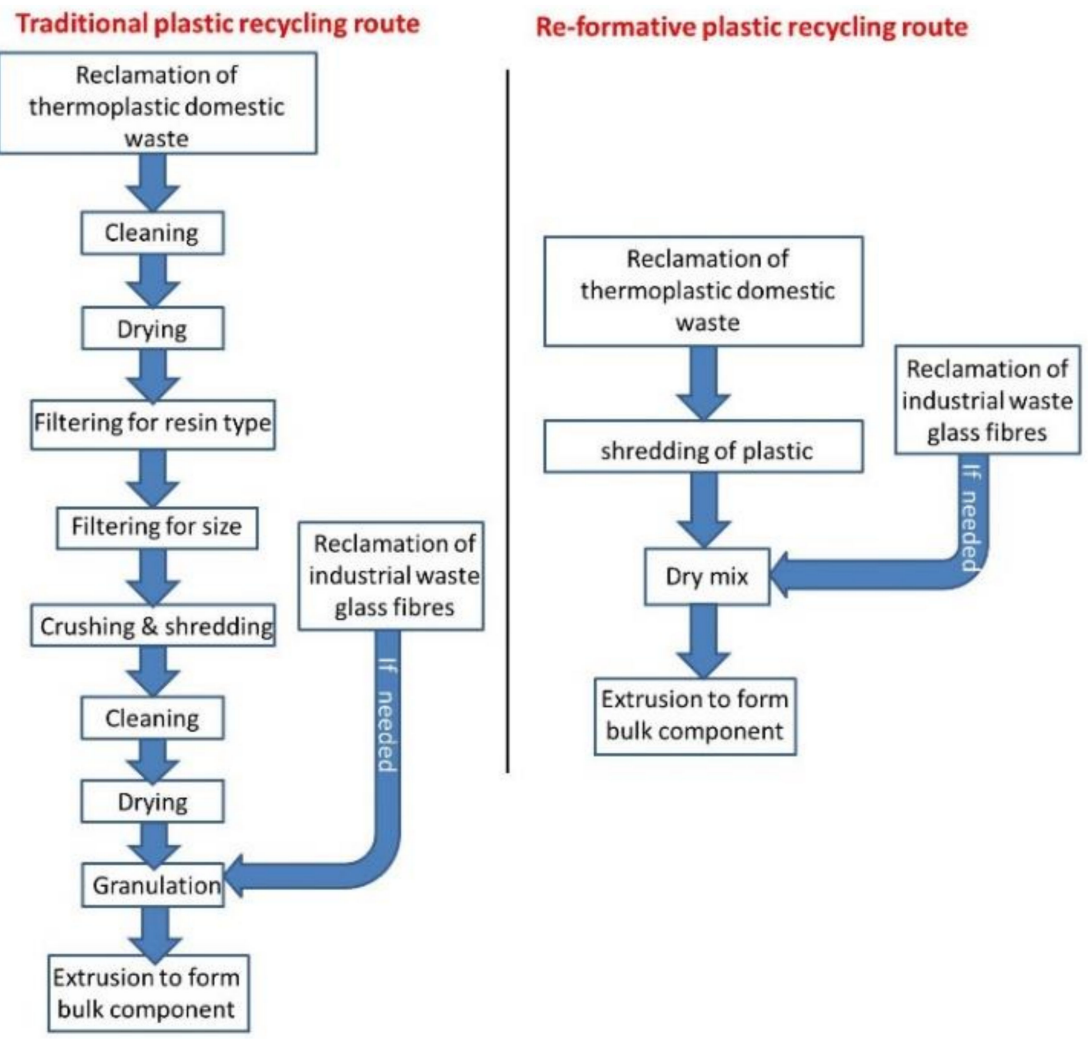

Figure 1. A schematic of the traditional plastic recycling process and the novel re-formative process.

\subsection{Novel Methods to Recycle Plastic Materials}

A novel polymer recycling process has been developed by Revaluetech Ltd., a UK-based company, which offers the means to produce heavy-duty composite products for a wide variety of applications in place of hardwood, treated softwood, and concrete. The process is able to increase production rates to industry-required levels and can process commingled plastic waste directly into finished products. Separately, a collaborative project between the University of Sheffield and Qatar University [18] led to the development of reinforced polymer composites from recovered commingled plastic waste material [17], which are able to match and exceed the strength characteristics of tropical hardwood, treated softwood, and unreinforced concrete products.

The process, called polymer re-formative engineering, is a multi-stage process whereby high volumes of industrial and domestic polymer material waste, which would typically be sent to landfill, can be transformed into structural components suitable for a wide range of engineering applications, including road and edging curbs, railway sleepers, noise barriers, coastal groynes, flood defences, revetments, and communications and utilities poles. The received commingled plastic waste can be taken in such large quantities that individual resin types are reasonably consistent within one sample to the next, simply through the statistics of sheer bulk quantity.

The recycled material then passes through a novel high speed filtering operation, where required, thus making it a faster, more efficient processing route than one slowed down by traditional washing and separation methods. Indeed, the recycled material can be contaminated by typical household debris, or even attached to metal foils or paper labels, such as is common with plastic packaging film and food containers. The presence of foreign bodies within the polymer matrix acts as a particulate strengthening mechanism toward the produced composite material.

The recycled waste is then shredded, dried, and fed into a single screw extruder, where glass fibres are added (according to application) during the initial melt phase of the polymers. This process results in a wide range of immiscible polymers being formed together into plastic composites. The extruded 
composite is fed directly into moulds of a desired shape and length, which are then cooled prior to ejection as the finished products [17].

Examples of industrial usage of recycled plastics for structural engineering applications are currently limited, but can be found amongst scientific and news literature, including Sekisui Chemical producing fibre reinforced railway sleepers [20], a UK Industry and University collaborative project again producing railway sleepers [21], and a new-to-market plastic lumber product with a range of applications [22]. Table 1 compares the strength and the Young (stiffness) Modulus of the re-formative polymer composite material with differing volume fractions of glass fibre added for particulate strengthening mechanisms to different grades of hardwood and softwood.

Table 1. Strength and modulus for different volume fraction glass fibre re-formative polymer composite, and for differing grades of hardwood and softwood.

\begin{tabular}{cccc}
\hline Material & Grade & Strength (MPa) & Modulus (GPa) \\
\hline \multirow{3}{*}{ Hardwood } & D70 & 70 & 20 \\
& D60 & 60 & 17 \\
& D50 & 50 & 14 \\
\hline \multirow{3}{*}{ Softwood } & C50 & 50 & 16 \\
& C40 & 40 & 14 \\
& C30 & 30 & 12 \\
\hline \multirow{3}{*}{ Re-formative polymer composite } & 30\% glass fibre & 116 & 5.35 \\
& 20\% glass fibre & 77 & 3.5 \\
& 15\% glass fibre & 58 & 2.7 \\
\hline
\end{tabular}

\section{Material}

A $120 \mathrm{~mm} \times 75 \mathrm{~mm} \times 75 \mathrm{~mm}$ block of re-formative polymer, without any glass fibre strengthening particulates, previously produced by Revaluetech Ltd (Birmingham, UK) using the process described in Section 1.2, was analysed (Figure 2a). Figure 2b highlights the cross-section of the block, and images (c) and (d) illustrate metallic foil and paper particulates in various orientations. The porosity observed at the centre of the cross section in Figure $2 b$ is believed to arise due to water vapour, which becomes trapped during the extrusion process. Upon cooling, the water vapour escapes, leaving behind the residual porosity features. The trapped water is likely a consequence of the removal of the drying operation after the flaking and chopping of the waste plastic, however, for safety-critical application products, the input shredded plastic material is dried prior to melt processing to prevent this.
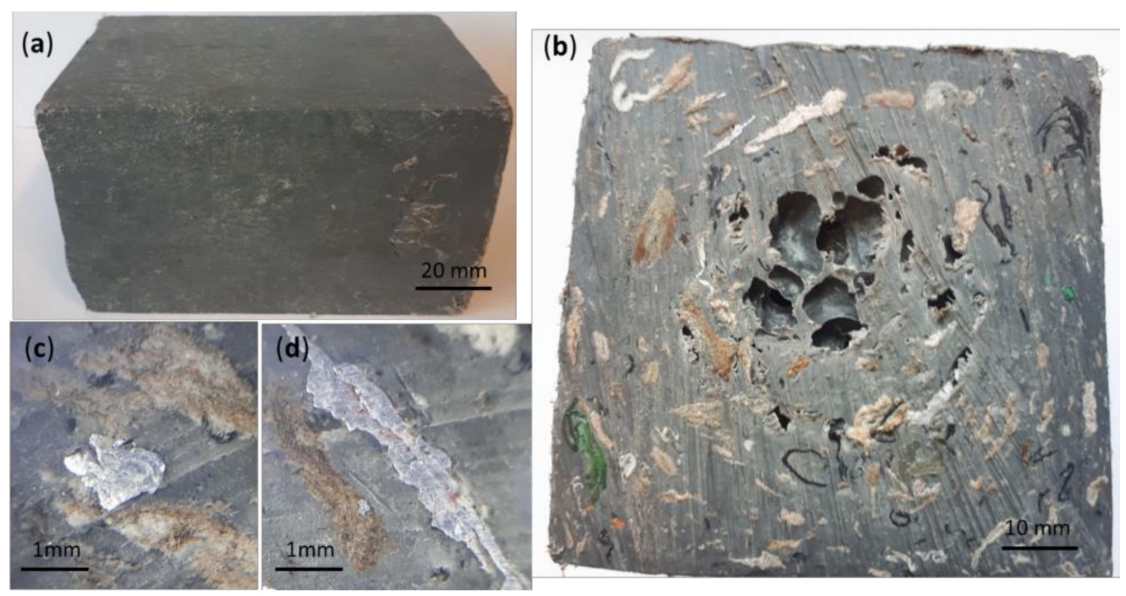

Figure 2. (a) Polymer composite 'block', (b) cross-section of the polymer, revealing (c) and (d) contaminants of aluminium foil and paper, providing additional particulate strengthening (work as part of this study). 
A Thermo Nicolet 8700 Infrared spectrometer (Thermo Fisher Scientific, Loughborough, UK) was used to analyse the polymer resin composition [23] at three locations across the re-formative block, namely a location close to the centreline, a location close to the edge of the block, and a location in between these. (see locations A, B, and C in Figure 2b). One hundred scans were carried out per sample with a resolution of $4 \mathrm{~cm}^{-1}$ and two level infilling.

Analysis of the resulting infrared spectrum (see Figure 3) confirms the dominant presence of both polypropylene and polyethylene as illustrated by the peaks at 2916 and $2848 \mathrm{~cm}^{-1}$ corresponding to the two different $\mathrm{CH}_{2}$ environments in both polymers and $2950 \mathrm{~cm}^{-1}$ corresponding to the $\mathrm{CH}_{3}$ group of polypropylene. A peak at $1715 \mathrm{~cm}^{-1}$ corresponding to the carbonyl group in the "contaminant" PET (allowed up to a tolerance within the recycled material) was also found. However, this variation throughout the surface of the block illustrates the potential for a small variation in composition due to contaminants within the material.

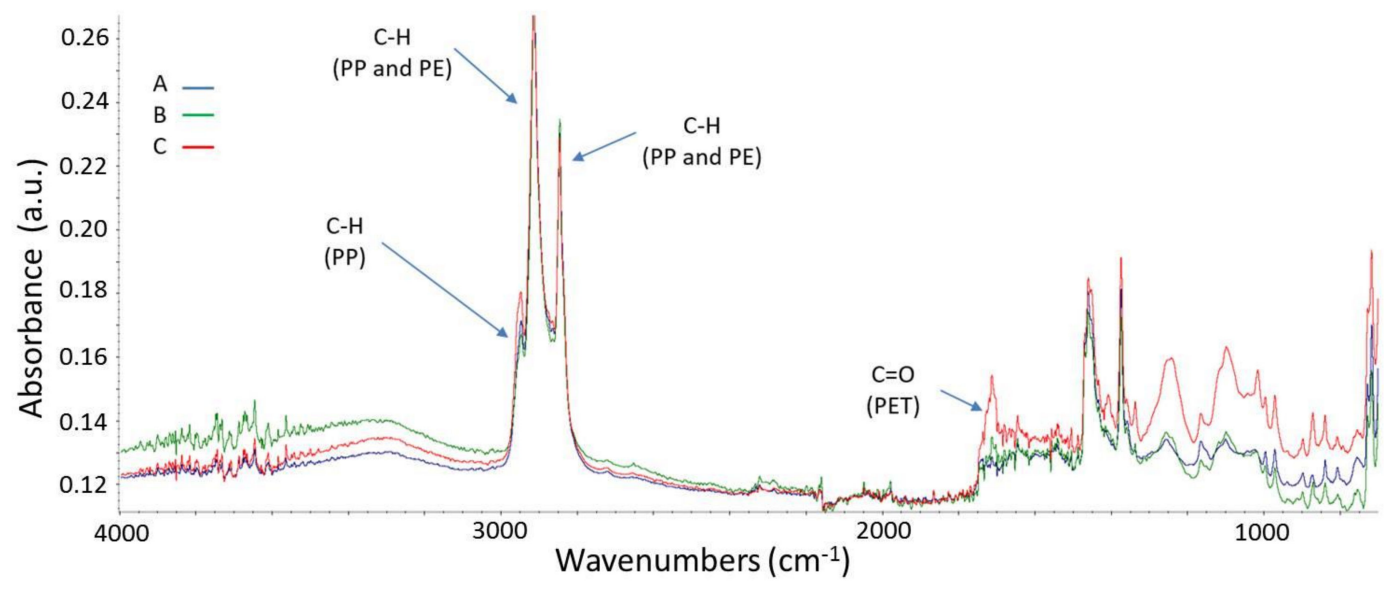

Figure 3. Infrared spectrum analysis of the re-formative polymer (this study).

The mechanical properties of the re-formative polymer must be a function of the relative compositions and proportions of polymers forming the recycled raw material inputted to the recycling process. Default mechanical properties for the re-formative polymer material are based upon an assumption of approximately 30\% each of HDPE, LDPE, and PP, with up to $10 \%$ allowed of "contaminant" debris and other polymer grades, such as PET. Given that the predominant source of the recycled raw material is consumer and commercial packaging, this limits the potential variation in the relative quantities of the HDPE, LDPE, and PP received, however, such variation must be considered when quantifying the mechanical properties of the re-formative material.

By considering the literature for data regarding re-formative polymer strength [18,19], and by considering the median value for the tensile yield strength and flexural yield strength of HDPE, LDPE, and PP from the literature [24], and allowing for a considerable increase or reduction in any given proportion of one of the three polymers up to $50 \%$ of the default $1 / 3$ value, an upper and lower bound for the estimated tensile and flexural yield strength can be formulated.

Fracture toughness $\left(\mathrm{K}_{\mathrm{IC}}\right)$ is another material property of considerable importance when analysing material suitability for a load-bearing application. This quantity describes the material resistance to brittle fracture within a mode I crack opening. A low value of fracture toughness, $\mathrm{K}_{\mathrm{IC}}$, suggests the material has little resistance to brittle fracture when a crack is present. A higher value of $\mathrm{K}_{\mathrm{IC}}$ suggests better resistance to brittle fracture. A ductile fracture allows for significant plastic deformation before rupture, which offers a significant margin of safety if components are regularly inspected. The fracture toughness of a polymer composite, concrete, and various types of wood are given in Table 2. In the case of wood, values are given assuming the crack is perpendicular to the grain. For wood, fracture toughness is predominantly related to the density. 
Table 2. Fracture toughness values for different materials.

\begin{tabular}{ccc}
\hline Material & Fracture Toughness $(\mathbf{M P a} \cdot \sqrt{\mathbf{m}})$ & Reference \\
\hline Polystyrene (PS) & $0.7-1.1$ & {$[25]$} \\
Poly(carbonate) (PC) & $2.0-4.0$ & {$[26]$} \\
Polyvinylchloride (PVC) & $2.0-7.5$ & {$[26]$} \\
Re-formative polymer composite (Thermoplastic) & $>7.5$ & {$[19]$} \\
(Thermoset) polymer epoxy composite (6\%) & $1.6-2.7$ & {$[27]$} \\
Concrete & $0.98-1.2$ & {$[28]$} \\
Pine (Softwood) & $0.5-3.0$ & {$[29]$} \\
Fir (Softwood) & $0.4-2.5$ & {$[29]$} \\
Oak (Hardwood) & $0.4-3.0$ & {$[29]$} \\
Mahogany (Hardwood) & $0.55-3.5$ & {$[29]$} \\
\hline
\end{tabular}

It is evident from Table 2 that the fracture toughness of polymers far exceeds that of concrete, and is comparable or better than the woods. Thus, the polymer re-formative material exceeds the current materials used in a load-bearing capacity in the applications targeted for the polymer composite. The addition of glass fibres to produce a reinforced composite will further increase the fracture toughness due to the bridging of fibres during plastic deformation. Note also that the fracture toughness compared to thermoset polymer (epoxy) composites is far greater, as thermoset polymer composites have always suffered substantially lower fracture toughness than thermoplastics [27].

\section{Experimental Procedure}

\subsection{Differential Scanning Calorimetry}

Differential scanning calorimetry (DSC) was used to determine the thermal properties of the re-formative block using a Mettler Toledo DSC 1/500 (Mettler-Toledo Ltd, Leicester, UK) [30] calibrated with indium and zinc standards. Samples (5-10 mg) were cut from three locations across the surface of the block (A, B, and C in Figure $2 \mathrm{~b}$ ) and weighed into standard $40 \mu \mathrm{L}$ aluminium DSC pans. The pan was capped with an aluminium DSC lid and sealed with a press as per the manufacturer's recommended procedure, before inserting into the DSC at room temperature, and cooling to $-50{ }^{\circ} \mathrm{C}$. The glass transition temperatures and melting point was taken when heating from -50 to $200{ }^{\circ} \mathrm{C}$ at a rate of $10^{\circ} \mathrm{C} / \mathrm{min}$.

\subsection{Dynamic Mechanical Thermal Analysis}

Dynamic mechanical thermal analysis (DMTA) was performed on the three samples from the locations within the re-formative polymer block, A B, and C (see Figure 2b), using a Netzsch DMA 242 (NETZSCH-Gerätebau GmbH, Wolverhampton, UK) [31], operated in the dual cantilever mode (length $10 \mathrm{~mm}$ ). The samples were heated from $25^{\circ} \mathrm{C}$ to $100^{\circ} \mathrm{C}$, at a rate of $2{ }^{\circ} \mathrm{C} / \mathrm{min}$, whilst being deflected by $15 \mu \mathrm{m}$ at a frequency of $1 \mathrm{~Hz}$. The DMA test is used to study the viscoelastic behaviour of the re-formative polymer blend as it undergoes an oscillating applied stress through the forced deflection using the displacement hammer, by measuring the storage and loss modulus parameters of the material [32].

\subsection{Porosity Analysis}

The porous bubbles, which were formed within the polymer block during extrusion, are caused by the presence of moisture within the shredded "dry" mix. Although no formal cleaning operation takes place within the re-formative polymer process route, some atmospheric moisture will be present on the consumer packaging. Moisture naturally found on polymers will cause some porosity during extrusion. However, the surface moisture content will be exacerbated given that (a) a considerable percentage of the packaging will have been a liquid container, such as drinks bottles; and (b) plastic 
material may be left exposed to the environment for a considerable time whilst gathering recycled material in sufficient quantities.

During extrusion processing, the "dry" mix is heated to $200^{\circ} \mathrm{C}$ within the extruder barrel, thus the water will entirely transform to vapour. Appropriate venting will allow the majority of the water vapour present in the polymer to exit the extruded material [33] once it breaks the surface, however, the residual moisture unable to escape will result in porosity.

The mass of the reformative polymer block was measured. The theoretical mass was calculated from the individual polymer densities using the known polymer resin fractions of $30 \%$ LDPE, $30 \%$ HDPE, and 30\% PP and assuming contaminant inclusions of 5\% polyethylene terephalate (PET) and up to $3 \%$ low density paper and aluminium foil. The porosity was then calculated via comparison of the actual to the theoretical mass.

\section{Results}

Figure 4 indicates both the tensile strength and the flexural strength of the re-formative polymer reinforced with varying amounts of glass fibres, added to the melt in an unstructured fashion to give a uniform strengthening of the composite polymer in all directions. This includes the upper and lower bounds based upon estimated variations in the proportions of HDPE, LDPE, and PP for the polymer.

It can be shown that the re-formative polymer alone has mechanical properties reasonably comparable to the virgin constituent polymers, which make up the recycled product. However, in a composite with reinforcing particulate fibres, significant improvements upon the flexural and tensile strengths can make the material a viable structural alternative.

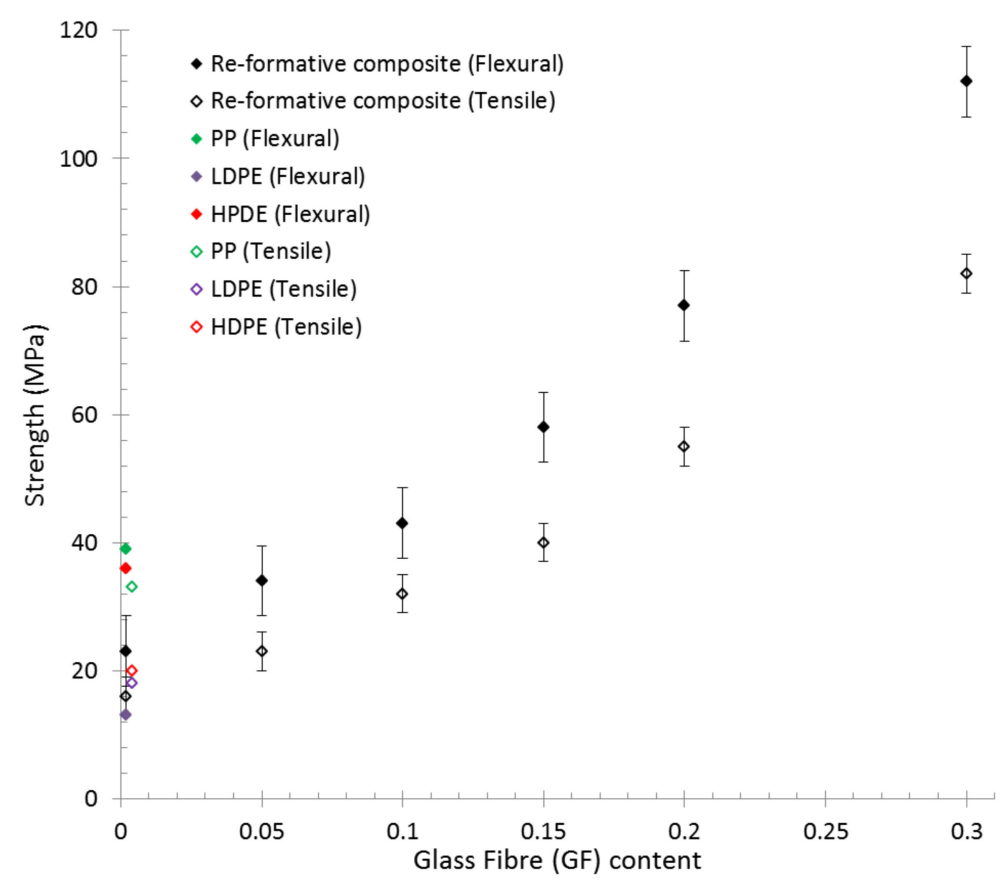

Figure 4. Graph illustrating the flexural strength and tensile strength of the polymer composite when reinforced with varying volume fractions of glass fibre (this study).

\subsection{Differential Scanning Calorimetry}

Results from the differential scanning calorimetry experiment traces (shown in Figure 5) indicates that for all three locations measured, central (A), intermediate (B), and edge (C) of the re-formative block, two glass transition temperatures and two melting points are evident. These are indicative of the glass transition and melting temperatures of polypropylene and polyethylene (see Table 3). The results were reasonably consistent across the different locations along the surface of the block, with a maximum variation in measured heat flow of approximately $10 \%$. The relatively low glass 
transition temperatures observed could potentially lead to some softening of the re-formative block if it were subject to prolonged exposure to sunlight/heat.

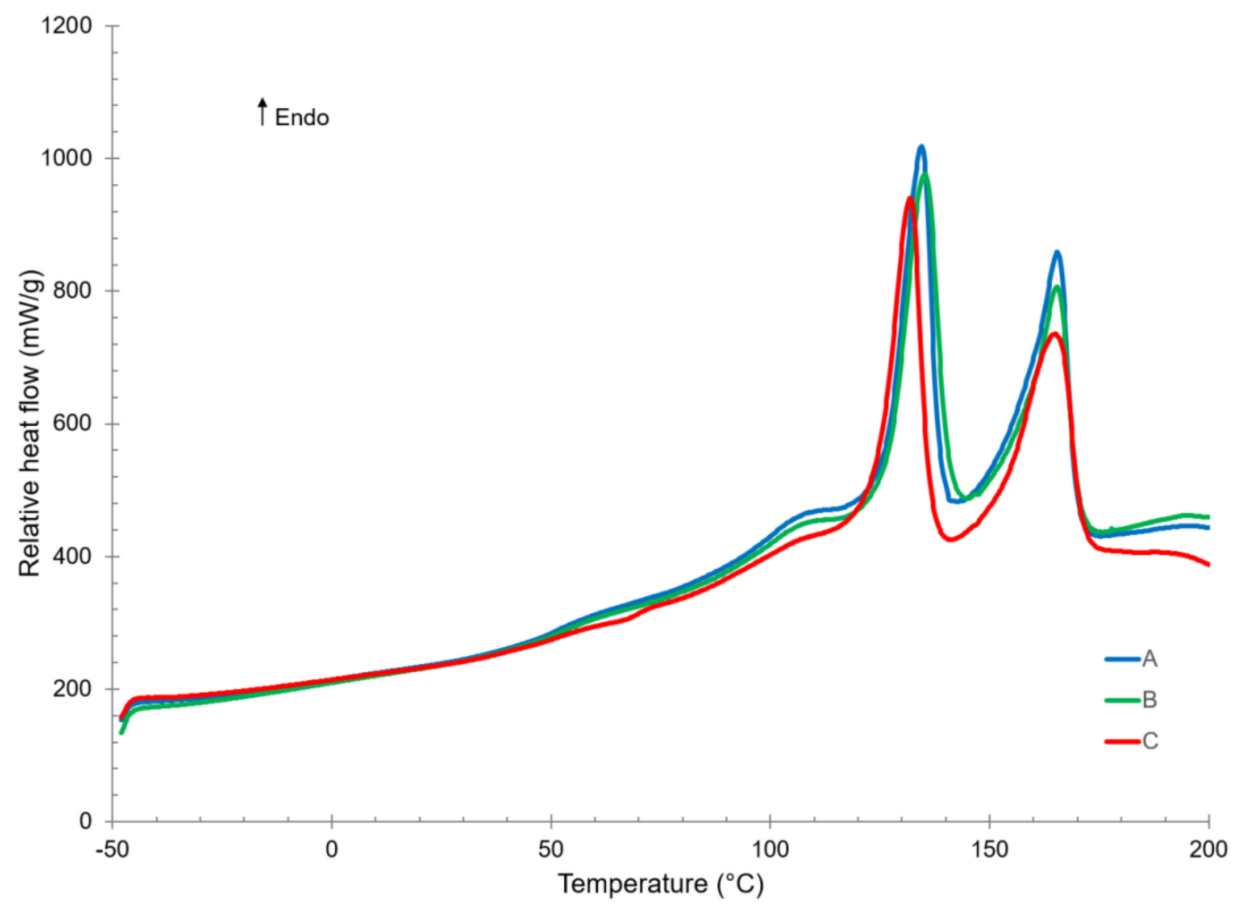

Figure 5. Differential scanning calorimetry (DSC) traces for three locations within the re-formative block (this study).

Table 3. Measured glass transition and melting temperatures measured at the three locations, A, B, and C (this study).

\begin{tabular}{ccccc}
\hline \multirow{2}{*}{ Sample } & \multicolumn{2}{c}{ Glass Transition Temperature $\left({ }^{\circ} \mathbf{C}\right)$} & \multicolumn{2}{c}{ Melting Point $\left({ }^{\circ} \mathbf{C}\right)$} \\
\cline { 2 - 5 } & $\mathbf{1}$ & $\mathbf{2}$ & $\mathbf{1}$ & $\mathbf{2}$ \\
\hline $\mathrm{A}$ & 51.2 & 99.3 & 134.5 & 165.3 \\
$\mathrm{~B}$ & 51.5 & 100.5 & 135.2 & 165.3 \\
$\mathrm{C}$ & 56.8 & 100.2 & 131.8 & 164.8 \\
Polymer & Unknown & Unknown & Polyethylene & Polypropylene \\
\hline
\end{tabular}

\subsection{Dynamic Mechanical Thermal Analysis}

The DMTA measures the viscoelastic properties of a material over time and can therefore analyse the softening of the material with elevated temperature. The results for two different test-pieces from location C (see Figure 2b) of the re-formative block are shown in Figure 6. The results show a slight decrease in both the storage and loss modulus on raising the temperature, which is indicative of material softening behaviour. A glass transition temperature is displayed in a DMTA trace by a large change in the storage modulus of over a decade, coupled with a peak in the tan delta. Neither of these were observed in this analysis, showing that the previously observed glass transitions in the DSC analysis have no impact upon the viscoelastic properties of the re-formative polymer. This could be due to the DMTA involving analysis over a large area of the re-formative block. 

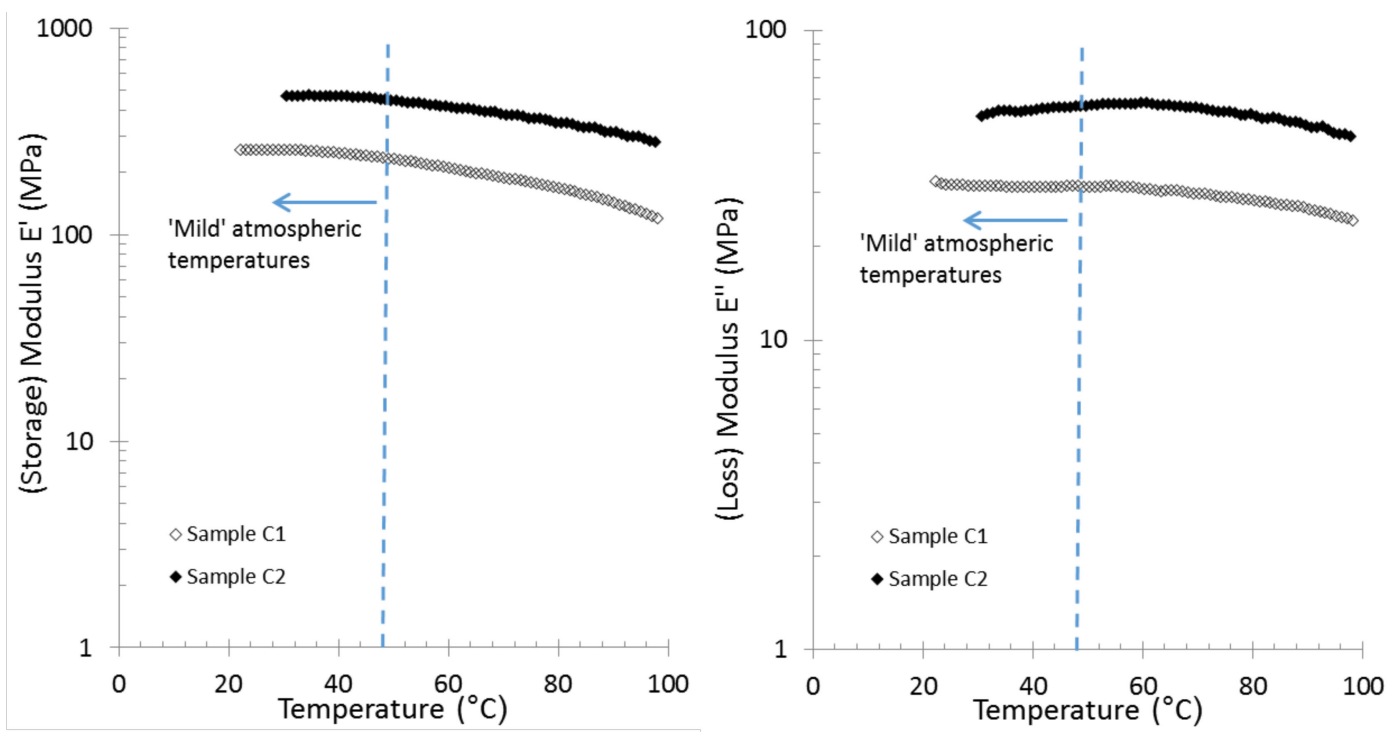

Figure 6. DMTA analysis of the polymer at two locations, $\mathrm{C} 1$ and $\mathrm{C} 2$, giving measurements of (left) the storage modulus and (right) loss modulus (this study).

In addition, no other large transitions occur during the temperature range analysed $\left(20^{\circ} \mathrm{C}-100{ }^{\circ} \mathrm{C}\right)$ indicating that, with the exception of softening with increasing temperature, the material will remain reasonably consistent over a considerable potential operating temperature range (up to $\sim 45^{\circ} \mathrm{C}$ ). Given that the ground temperature can vary slightly from air temperature when the material is in-service as a structural component, for ground-based applications, such as railway sleepers or curbing, the user must keep this operating window in mind. However, for potential locations of re-formative polymer composite components, which experience relatively mild peak summer temperatures, Figure 6 suggests that there is only very small degradation in the elastic modulus, and not enough to cause concern for components exposed to these atmospheric temperatures for a prolonged period of time.

The considerable difference in storage modulus and loss modulus values between specimens, $\mathrm{C} 1$ and $\mathrm{C} 2$, arise due to the presence of additional aluminium foil contaminant in specimen $\mathrm{C} 2$, which has increased both values considerably at this location. The presence of contaminant foil/paper, or the glass fibres, was considered as potential plasticizers in the polymer matrix. However, the DMTA results show that when passing through the glass transition of each component, there is no effect on the overall viscoelastic properties of the bulk re-formative polymer brick.

\subsection{Porosity}

Even for this uncleaned, undried recycled material, the presence of moisture only remains a minor issue, producing a small number of clustered voids. The interior surface of the void region indicated in Figure 2 was examined further. A network of smooth surfaced interconnected passages can be seen (Figure 7) connecting to the large void. This would strongly suggest that the porous void features are formed by water vapour present within the material as it was being heated and extruded.

However, in some safety critical applications, where the re-formative polymer is a potential material of interest, the presence of voids is highly undesirable, as they can act as nucleation sites for failure events. The sample pictured in Figure 2 was measured for voids, and using the known polymer resin volume fractions. A void volume fraction of between $1.5 \%$ and $3.0 \%$ was calculated, which can be reduced to a negligible void volume fraction by pre-drying [33] the chopped and shredded "dry" mix.

The non-polymer contaminants themselves could potentially act as nucleation sites for voids to form. This type of defect would form if the bond between the polymer matrix and the particulate paper, aluminium foil, or other contaminant was weak. However, the nature of the shredding operation would likely leave very rough surfaces on the contaminants, which would in turn leave a rough surface 
on the inside of a porous feature, thus it is unlikely that those observed in Figure 7 are caused by delamination issues.

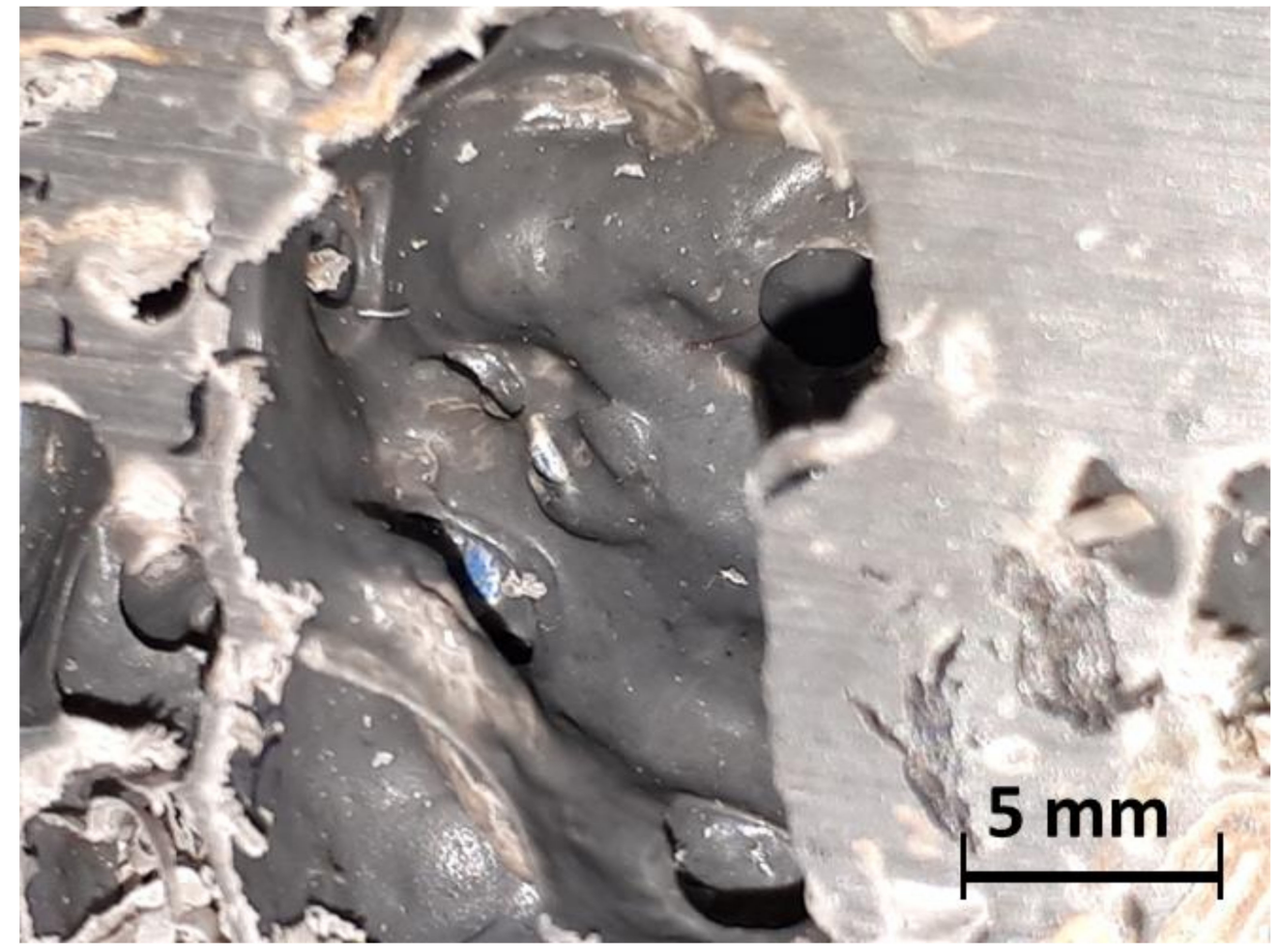

Figure 7. The interior of a porous region within the re-formative polymer (this study).

\section{Discussion}

\subsection{Environmentally Friendly Beyond Plastics Pollution}

Whilst the re-formative polymer composite product is primarily aimed as a sustainable means to recycle commingled plastics waste and thus the reduction of plastics pollution, it has concomitant environmental benefits in addition to this. Other typical materials used in the construction of the products and components that this re-formative polymer composite is suitable for, such as marine pilings, utility poles, and revetments, include treated softwoods or tropical hardwoods. Softwoods typically possess a bulk strength of roughly $30-50 \mathrm{MPa}$. In the case of treated softwoods, creosote is the most widely used chemical treatment to protect the surface. Creosote is a tar substance produced as a by-product of the processing of fossil fuels. However, it is known to be carcinogenic and as such the use of creosote as a preservative agent for wood is highly regulated. As a result, in May this year, creosote was banned by the European Union and therefore the UK is undergoing a process to prevent any creosote-treated wood being used [34]. However, exemptions have been granted allowing creosote treatment of railway sleepers and utility poles until 2021.

A European Commission [35] report on the use of creosote suggested that no other method of treating softwoods for surface impregnation, nor steel or concrete manufactured sleepers, would produce significant environmental benefits compared to creosote impregnated wood. The report does not, however, consider alternative recycled materials to wood and concrete. The current alternative to using softwood may be a tropical hardwood, which has a typical flexural strength of 50 to $80 \mathrm{MPa}$, however, these are more expensive and the environmental impacts of large scale deforestation of tropical hardwoods makes this a highly undesirable alternative material in these applications. Even comparisons of environmental impacts for the re-formative polymer composite compared to concrete show significant carbon emission reductions, saving up to $95 \%$ [36]. 


\subsection{Applications}

The service lifetime of such components made from hardwoods and softwoods, compared to the re-formative plastic composite, must also be factored into an assessment of material selection. In the case of utility poles, new installations do not require testing until they are 12 years old, and thereafter require testing at regular intervals for structural suitability. Typically, the lifetime of a wooden utility pole is approximately 35 years [37], although this will be dependent upon the weather and conditions of its location. Accelerated ageing tests were carried out in 1996 predicting signs of deterioration of these polymer composites after 300 years [38].

Coastal groynes are occasionally used to provide a managed mitigation strategy against coastal erosion [39]. For coastal locations in particular, the chemical aggressiveness of brine, potentially containing pollutants, at ambient temperatures increases deterioration rates for wood [40]. In addition, sand, shingle, and attack by boring grubs (shipworm and gribble) severely decreases the effective service life where lumber is used.

In the case of a UK-based coastal groyne structure, repair and replacement of worn wooden lumber with polymer lumber has proven a successful exercise [41], with installations containing polymer composite lumber replacements for eroded wooden ones shown in Figure 8a. Due to the relatively high wear rate caused by the location and environmental conditions [40], wear rates of the wooden and re-formative polymer were compared. Figure $8 \mathrm{~b}$ illustrates almost no wear evident on the re-formative polymer unit, compared to substantial wear observed on the wooden lumber unit.

(a)

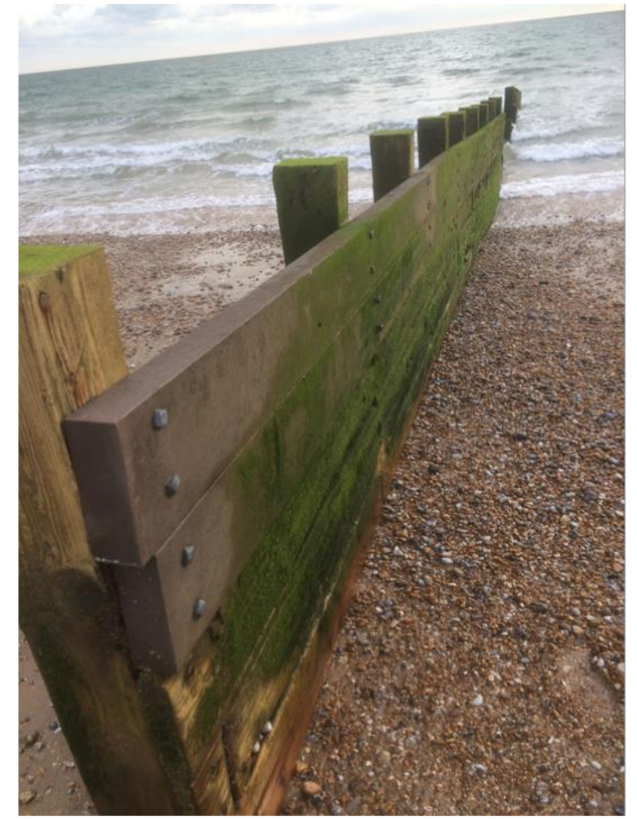

(b)

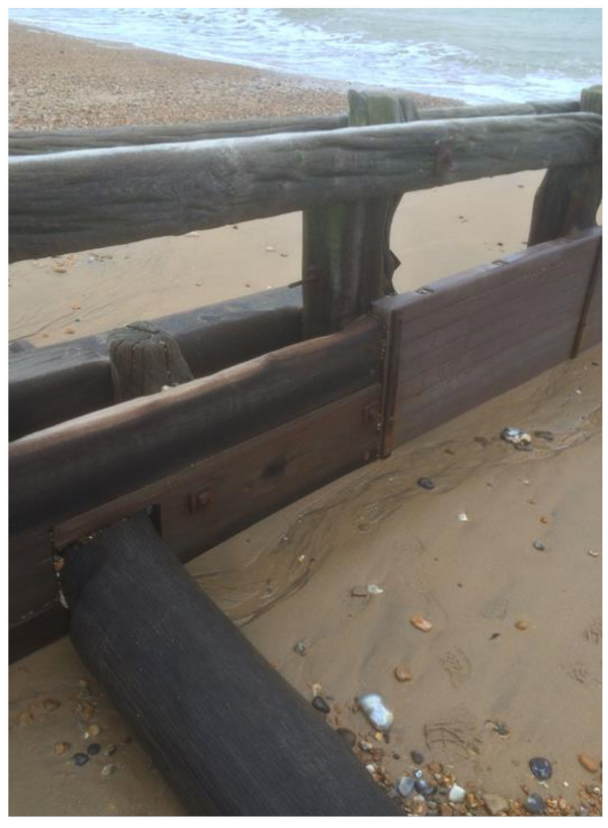

Figure 8. (a) Successfully repaired groyne with the re-formative polymer, and (b) evidence after 12 years of less wear and erosion on the re-formative polymer compared to the greenheart tropical hardwood boards.

Clearly, there is a considerable cost associated with the replacement of groyne structures, particularly when replacing the vertical piles, which must be driven into the ground. This repair and replacement activity requires considerable engineering work. Thus, reducing the frequency of replacement offers clear financial benefits. As such, it is believed that there is considerable environmental potential when using the re-formative polymer composite material to form structurally load bearing engineering components in place of the wooden ones for both high wear rate applications and high strength applications. 


\subsection{Recycled Glass Fibre Material}

Whilst the polymer composite material is largely formed using recycled domestic plastic waste, the recycled material within the polymer composite goes even further. The reinforcing glass fibres used to add strengthening mechanisms can also be sourced from an estimated 11,000 tonnes per annum of reject glass fibre material at present being sent to landfill [42]. Future development programs for materials' recycling aims to extend the use of recycled glass fibre to use fibre recovered from glass-reinforced plastic (GRP) products, such as wind turbine blades and boat hulls [43]. A developmental process to extract glass fibres from the encasing resin with only $5 \%$ resin contamination is being studied. Currently, there is little recycling opportunity for GRP material due to the fact that it is commonly manufactured using a thermoset polymer. However, this was the subject of an European Composites Industry Association (EuCIA) report highlighting that GRP waste products should be recyclable, using a process as defined in the literature [44]. GRP recycling facilities as of 2013 were limited to Germany [43]. However, carbon fibre reinforced plastic recycling methods are developing via pyrolysis based approaches [45] to attempt to reduce the quantity that ends up in landfill. A sustainable recycling process to provide an alternative outlet for GRP scrap is highly desirable.

\subsection{Cost Analysis}

As with any new-to-market product competing with established alternatives, there must be a consideration toward the raw material and manufacturing costs for the finished component. Thus, cost analyses will be broken down to focus upon different applications to understand the potential cost-saving of the re-formative polymer composite in each system.

\subsubsection{Edging Curbs to Replace Concrete}

A $100 \mathrm{~m}$ section of re-formative polymer composite edging curb would cost roughly $£ 153$. This is comparable to the $£ 156$ estimated for concrete, although this does not factor into any cost calculation the $\sim 10 \%$ breakage of concrete edging curbs in transportation, repair costs involved with concrete compared to almost negligible repair costs for the re-formative polymer due to their high fracture toughness, and extra transportation costs of concrete due to the higher density. Estimates suggest a $50 \%$ overall cost saving with the re-formative polymer curbs compared to concrete, see Figure 9 . The polymer units can be cut by a simple mechanical handsaw compared to specialist saws required for cutting concrete. The re-formative polymer would generate minimal dust, which would not be carcinogenic, compared to the carcinogenic RCS dust emitted from cutting concrete, further enhancing the environmental impact this polymer composite offers. This component is currently produced in annual quantities of 1.5 million by a leading UK supplier, thus offering substantial savings.

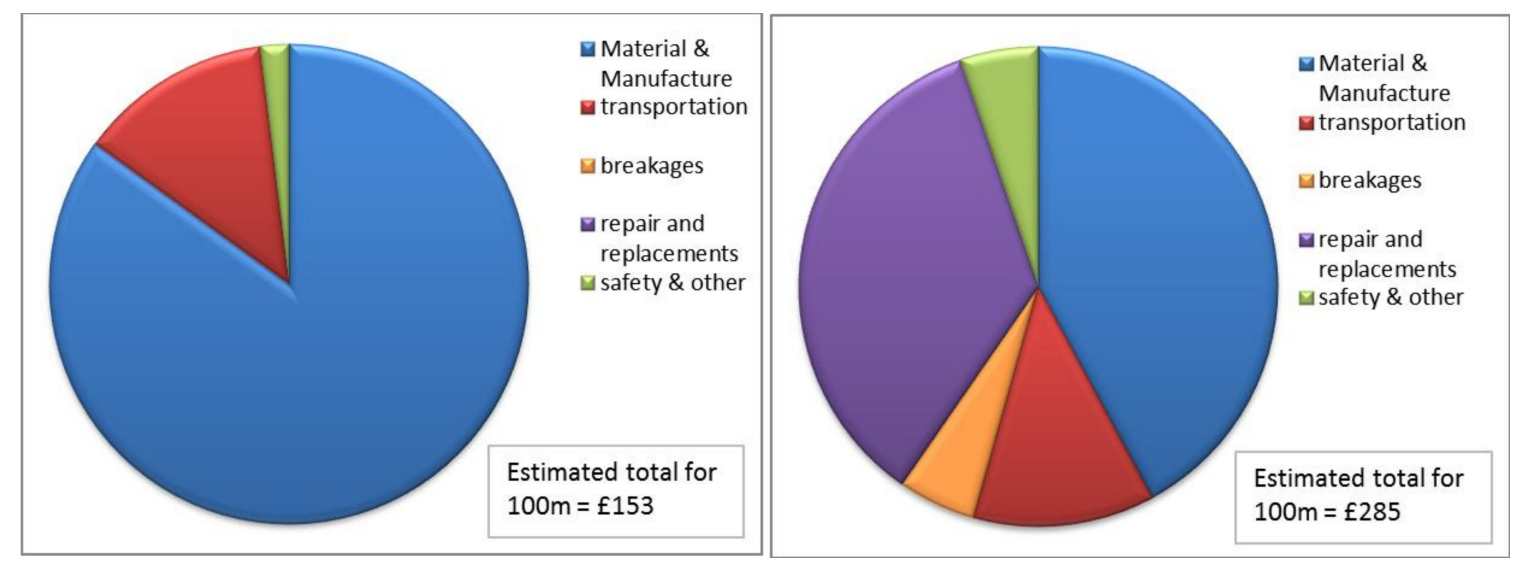

Figure 9. Cost analysis for $100 \mathrm{~m}$ edging curb units, re-formative polymer composite vs concrete (this study). 


\subsubsection{Utility Poles to Replace Hardwood}

Current estimates for the cost of creosote-treated wooden utility poles measuring $250 \mathrm{~mm}$ diameter and $12 \mathrm{~m}$ in length are $£ 250$ per unit. In comparison, a polymer composite $250 \mathrm{~mm}$ diameter by $12 \mathrm{~m}$ long pole would be more expensive at roughly $£ 350$ each. However, demand for a replacement material for these utility poles is growing in urgency due to the creosote ban (the exemption being used by the power, telecoms, and rail sectors ceases in 2021), and as such the slight cost differential moving toward a polymer composite may not pose a problem when consideration is given toward the longer effective service life predicted for a polymer composite.

\subsubsection{Revetments to Replace Concrete}

A mass produced concrete fence post of approximately $2.5 \mathrm{~m}$ ( 8 foot) costs $£ 7.60$ in raw material and manufacturing costs. Slotted concrete gravel boards, which fit in between the fence posts to form the revetment, costs $£ 7.80$ in material and manufacturing costs. These two components are produced by a UK supplier in annual quantities of 50,000-60,000. A polymer composite replacement for the post would retail at roughly $£ 5.00$, and similarly for the slotted board. This could therefore yield cost savings of approximately $£ 325,000$ to this one supplier alone.

\subsection{Economic Summary}

Within its role as a more economically developed nation with an advanced economy, a signatory member of the Paris Agreement on climate change, and a considerable plastics producer on the global scale, the United Kingdom must take a lead position in the development, certification, and global adoption of new manufacturing methods, which can aid in the reduction of pollution, fossil fuel reliance, deforestation, and other environmental concerns. Taking a lead role in these novel processing route developments includes investing capital into the polymer recycling industry in order to support small-scale testing facilities to perform proof-of-concept studies, safety assessments, and process quantification, and additional investment within the industry to support pilot-scale facilities to perform scale-up tests to demonstrate large-scale industrial relevance. However, the cost analysis, in addition to new guidelines and laws concerning the environment, demonstrates that this proposed novel methodology can be financially viable as well as being environmentally beneficial.

\section{Conclusions}

A re-formative polymer composite manufacturing route has been established, which offers the plastics community and the environment a number of specific benefits:

- The process does not require detailed filtering for plastic types, and does not require a thorough cleaning operation of the recycled material. In fact, the presence of particulate contaminants, such as paper or metal foils, from the original plastic use acts as particulate strengthening to the polymer composite. The polymer composite can be strengthened further with the addition of glass fibres to the chopped mix, if the application is so required;

- The re-formative polymer glass transition temperature, melting temperature, and elastic modulus have been measured, indicating the potential for use of this material in locations with mild to moderate peak summer temperatures;

- The polymer composite was considered for replacing concrete usage in certain applications. This could have a significant reduction in carbon emissions associated with concrete production, and remove the generation of carcinogenic particulate dust formed when concrete is cut;

- The polymer composite was considered for replacing the use of either tropical hardwood or treated softwood in some applications. This could have significant impact upon reducing deforestation, and also remove the need for creosote-type carcinogenic agents on the wood surface, which may leach out of the coating and into the environment over time, and the dependency upon fossil fuel processing. 
For further study, the authors would propose the following work: (i) An extended assessment on the suitability of the re-formative polymer composite in specific atmospheric conditions, including a study regarding the mechanical property variation when the re-formative polymer is exposed to levels of Ultra Violet radiation (UV) and moisture, as this current study has been limited to considerations of the mechanical response with exposure to temperature; (ii) a study on the impact of exposure to saltwater upon the mechanical properties and the structural use of the re-formative polymer; (iii) a study upon the cooling rate of the re-formative polymer as it is extruded, and how this could impact upon the crystallisation of the mixed polymer types; and (iv) a more detailed consideration on the inclusion of contaminants in the recycled material, including paper and foil labels, to determine an optimised composition of the contaminants.

Author Contributions: R.P.T. is the lead author. He collated the literature review, performed mechanical and microscopy analysis, drafted the manuscript, and co-ordinated the submission. C.A.K. performed the polymer science literature review and work, B.H. and R.F. assisted with proof-reading the manuscript, providing material, and with data analysis.

Funding: This research was part-funded by the European Regional Development Fund (ERDF), with grant number [12R15P00243].

Acknowledgments: This article has been written as a part of the ERDF part-funded AMCASH project. AMCASH is a project co-ordinated by the University of Birmingham, aiming to support regional SME organisations in the fields of polymer engineering and science, materials characterisation methods and computational modelling.

Conflicts of Interest: The authors declare no conflict of interest

\section{References}

1. Jones, R.A.L. Soft Condensed Matter; Oxford University Press (OUP): Oxford, UK, 2002.

2. Practical Action Ltd. Mechanical Waste Plastic Recycling-A Technical Brief, Practical Action Ltd., The Schumacher Centre, Bourton-on-Dunsmore, Warwickshire CV23 9QZ UK. 2010. Available online: https: / / answers.practicalaction.org/our-resources/item/mechanical-waste-plastic-recycling-technical-brief (accessed on 22 November 2018).

3. Wassener, B. Raising Awareness of Plastic Waste, The International Herald Tribune. 2011. Available online: https:/ / www.nytimes.com/2011/08/15/business/energy-environment/raising-awareness-of-plasticwaste.html (accessed on 22 November 2018).

4. British Plastics Federation, BPF House, Rivington St, London, UK. Available online: http://www.bpf.co.uk/ Industry/Default.aspx (accessed on 22 November 2018).

5. Lyons, K. Only a Third of UK Consumers' Plastic Packaging Is Recycled, The Guardian (UK Edition). November 2016. Available online: https:/ / www.theguardian.com/environment/2016/nov/21/only-athird-of-uk-consumer-plastic-packaging-is-recycled (accessed on 22 November 2018).

6. Parveen, N. UK's Plastic Waste May Be Dumped Overseas Instead of Recycled, The Guardian (UK Edition). 2018. Available online: https:/ / www.theguardian.com/environment/2018/jul/23/uks-plastic-waste-maybe-dumped-overseas-instead-of-recycled (accessed on 22 November 2018).

7. D'Alessandro, N. Twenty-two Facts About Plastic Pollution, EcoWatch. 2014. Available online: https://www. ecowatch.com/22-facts-about-plastic-pollution-and-10-things-we-can-do-about-it-1881885971.html (accessed on 22 November 2018).

8. Peplow, M. The plastics revolution: How chemists are pushing polymers to new limits. Nature 2016, 536, 266-268. [CrossRef] [PubMed]

9. Carrington, D. Micro-Plastic Pollution in Oceans Is Far Worse than Feared, The Guardian (UK Edition). 2018. Available online: https:/ / www.theguardian.com/environment/2018/mar/12/microplastic-pollution-inoceans-is-far-greater-than-thought-say-scientists (accessed on 22 November 2018).

10. Brandrup, J. (Ed.) Recycling and Recovery of Plastics; Hanser Verlag: Munich, Germany, 1996; ISBN $1569902143-9781569902141$.

11. La Mantia, F.P. Handbook of Plastics Recycling; Rapra Technology: Shrewsbury, UK, 2002; ISBN 1-85957-325-8.

12. Vilaplana, F.; Karlsson, S. Quality concepts for the improved use of recycled polymeric materials: A review. Macromol. Mater. Eng. 2009, 293, 274-297. [CrossRef] 
13. Xanthos, M.; Grenci, J.; Patel, S.H.; Patel, A.; Jacob, C.; Dey, S.; Dagli, S.S. Thermoplastic composites from maleic anhydride modified post-consumer plastics. Polym. Compos. 1995, 16, 204-214. [CrossRef]

14. Xanthos, M.; Narh, K.A. Product design with glass fiber reinforced polymer blends, with potential applications in recycling. Polym. Compos. 1998, 19, 768-780. [CrossRef]

15. Hunter, A. Greenpeace Article “Nine Ways to Reduce Your Plastic use". 2017. Available online: https: / / www.greenpeace.org.uk/9-ways-reduce-plastic-use/ (accessed on 22 November 2018).

16. McCallum, W. How to Give Up Plastic; Penguin Books: London, UK, 2018; ISBN 9780241363218.

17. AlmMa'adeed, M.A.; Madi, N.; Hodzic, A.; Rajendran, S. Reinforced Polymer Composites from Recycled. Plastic. Patent No. US 9309392B2, 2 April 2016. Available online: https://patents.google.com/patent/ US9309392B2/en (accessed on 22 November 2018).

18. Scelsi, L.; Hodzic, A.; Soutis, C.; Hayes, S.A.; Rajendran, S.; AlMa'adeed, M.A.; Kahraman, R. A review on composite materials based on recycled thermoplastics and glass fibres. Plast. Rubber Compos. 2011, 40, 1-10. [CrossRef]

19. Rajendran, S.; Scelsi, L.; Hodzic, A.; Soutis, C.; Al-Maadeed, M.A. Environmental impact assessment of composites containing recycled plastics. Resour. Conserv. Recycl. 2012, 60, 131-139. [CrossRef]

20. Sekisui Chemical, Co. Ltd., 2-3-17 Toranomon, Minato-ku, Tokyo 105-8450 Japan. Available online: https: //www.sekisui-rail.com/en/ (accessed on 22 November 2018).

21. The Telegraph (Road and Rail Transport). 2009. Available online: https://www.telegraph.co.uk/news/ uknews / road-and-rail-transport/5274149/Network-Rail-to-replace-wooden-sleepers-with-recycledplastic.html (accessed on 22 November 2018).

22. HAHN Plastics Ltd., Manchester United Kingdom. 2012. Available online: https://www.hahnplastics.com/ en/ (accessed on 22 November 2018).

23. Thermo Fisher Scientific-Europe. Available online: https://www.thermofisher.com/uk/en/home.html (accessed on 22 November 2018).

24. MATWEB Material Property Data. Available online: http://www.matweb.com/Search/ MaterialGroupSearch.aspx?GroupID=15 (accessed on 22 November 2018).

25. Serrano, A.M.; Welsch, G.E.; Gibala, R. An electrical method of measuring crack length during propagation tests of polymers. Polym. Eng. Sci. 1982, 22, 946-949. [CrossRef]

26. Major, Z.; Lang, R.W. Rate Dependent Fracture Toughness of Plastics. Eur. Struct. Integr. Soc. 2003, 32, 187-198. [CrossRef]

27. Zamanian, M.; Mortezaei, M.; Salehnia, B.; Jam, J.E. Fracture toughness of epoxy polymer modified with nanosilica particles: Particle size effect. Eng. Fract. Mech. 2013, 97, 193-206. [CrossRef]

28. Hamoush, S.A. The fracture toughness of concrete. Eng. Fract. Mech. 1996, 53, 425-432. [CrossRef]

29. Ashby, M.F.; Easterling, K.E.; Harrysson, R.; Maiti, S.K. The Fracture and Toughness of Woods. Proc. R. Soc. Lond. Ser. A Math. Phys. Sci. 1985, 398, 261-280. [CrossRef]

30. Mettler-Toledo Ltd., Laboratory Analytical Instruments Group; Beaumont Leys: Leicester, UK. Available online: https:/ / www.mt.com/gb/en/home.html (accessed on 22 November 2018).

31. NETZSCH-Gerätebau GmbH, Hilton Cross Business Park, Wolverhampton, WV10 7FE, UK. Available online: https:/ / www.netzsch.com/en / (accessed on 22 November 2018).

32. Nikolaidis, A.; Labuza, T.P. Use of dynamic mechanical thermal analysis (DMTA). J. Therm. Anal. 1996, 47, 1315. [CrossRef]

33. AMETEK. Arizona Instrument, Monitoring Water Concentrations in the Extrusion Process. Available online: https://www.azic.com/monitoring-water-concentrations-in-the-extrusion-process/ (accessed on 22 November 2018).

34. The Health and Safety Executive (HSE). REACH Regulation EC No. 1907/2006; HSE: Bootle, UK, 2006.

35. European Commission. Unit B.3, Creosote Consultation BU 9-06/129; European Commission: Brussels, Belgium, 2008.

36. Revaluetech Ltd Edge Kerb Comparison; Internal Report. Available online: http:/ /www.industrialbuyer.co. uk/revaluetech-has-the-main-solution---ibdm.html (accessed on 22 November 2018).

37. Morrell, J.J. North American Wood Pole Council-Technical Bulletin. 2016. Available online: https:// woodpoles.org/portals/2/documents/TB_ServiceLife.pdf (accessed on 22 November 2018).

38. AEA Technology-Physical and Environmental Test Report. 1996. Available online: https://data.gov.uk/ data/contracts-finder.../ff9469d3-508f-471c-93ee-fdc54e11505c (accessed on 22 November 2018). 
39. O’Brien, P. Coastal Engineering Solutions, 2014. Available online: http://www.coastengsol.com.au/groynesfor-what-purpose/ (accessed on 22 November 2018).

40. Jolly, C.K. Fibre composites in coastal and river defences, Chapter 8-Case Studies. In Advanced Polymer Composites for Structural Applications in Construction (ACIC); Hollaway, L.C., Chryssanthopoulos, M.K., Moy, S.S.J., Eds.; Woodhead Publishing: Cambridge, UK, 2004; ISBN 978-1-85573-736-5.

41. Cronin, B. Sea Defences-Broomhill Sands Coastal Scheme, New Civil Engineer. 2016. Available online: https:/ / www.newcivilengineer.com/technical-excellence/sea-defences-broomhill-sands-coastal-scheme/ 10001176.article (accessed on 22 November 2018).

42. Wait, C.F. The Reuse and Recycling of Glass Fibre Waste. Master Thesis, University of Birmingham, Birmingham, UK, 2010.

43. Job, S. Recycling composites commercially. Reinf. Plast. 2014, 58, 32-38. [CrossRef]

44. Recycling and Sustainability Platform of the European Composites Industry Association (EuCIA). 2011. Available online: http:/ / www.ecocomposites.net/index.php?option=com_content\&view=article\&id=10164 (accessed on 22 November 2018).

45. ELG Carbon Fibre Ltd., Coseley, United Kingdom. 2017. Available online: http://www.elgcf.com/ (accessed on 22 November 2018).

(C) 2018 by the authors. Licensee MDPI, Basel, Switzerland. This article is an open access article distributed under the terms and conditions of the Creative Commons Attribution (CC BY) license (http:/ / creativecommons.org/licenses/by/4.0/). 